\title{
EFICIÊNCIA ECONÔMICA DO SEGMENTO DA MADEIRA COMPENSADA NO ESTADO DO PARANÁ
}

\author{
Willian Borelli Polzl ${ }^{1}$ \\ Anadalvo Juazeiro dos Santos ${ }^{2}$ \\ Ricardo Berger ${ }^{2}$ \\ Luiz Roberto Graça ${ }^{3}$ \\ Priscilla Klingelfus Polzl ${ }^{4}$
}

\section{RESUMO}

O segmento produtivo da madeira compensada passa por reestruturações mundiais, este artigo tem como objetivo analisar a eficiência econômica deste segmento para propor medidas estratégicas às empresas do segmento, através da análise de sua eficiência econômica. Neste sentido, são analisados indicadores de Lucratividade e Índice de Eficiência Econômica. Os dados foram obtidos durante os meses de Março a Maio de 2002, através de amostragem de 32\% das empresas e 39,79\% do volume produzido no Paraná. Observa-se que as empresas que fabricam compensados decorativos possuem as maiores lucratividades, as empresas de compensados de Pinus apresentam eficiência econômica maior. Bem como as empresas de pequeno porte embora sejam predominantes são, em geral, as menos eficientes e menos lucrativas. Através destas informações foi possível embasar e definir estratégias empresariais e setoriais.

Palavras Chave: floresta; economia florestal; madeira

\section{ECONOMIC EFFICIENCY OF THE PLYWOOD SECTOR IN THE STATE OF PARANA}

\section{ABSTRACT}

The economic history of Paraná State has shown a close linkage to the Forest sector, and nowadays this sector still has a large influence in the State's economy. For this reason, economic and productive evaluation of the plywood segment is relevant in order to provide information for strengthening the industrial timber sector as a whole, and specifically the veneer and plywood industry. This study tackles on identifying the economic eficiency of these industries. The data used in this research was gathered through a questionnaires addressed to a number of 39 plywood manufacturing firms (32\% of all). The sampling was carried out between the months of March and May of 2002, and gave elements to caculete indexes of cost structure, profitality and the Economic Efficiency Rate (IEE). This study could be used as a reference for the sector's planning and also for establishing public policy in the State of Paraná.

Key words: forest economy, forest, wood

\footnotetext{
${ }^{1}$ Doutorando em Engenharia Florestal, UFPR.wpolzl@floresta.ufpr.br

${ }^{2}$ Professores do programa de Pós Graduação em Engenharia Florestal da UFPR, Brasil

${ }^{3}$ Pesquisador da Empresa Brasileira de Pesquisa Agropecuária - EMBRAPA - CNPF

${ }^{4}$ Mestranda em Engenheira Florestal, UFPR
}

Recebido para publicação: 18/02/2003

Aceito para publicação: 28/07/2003 


\section{INTRODUÇÃO}

O segmento da madeira compensada no Brasil apresentou um crescimento relevante na sua produção e este crescimento estava voltado principalmente para a exportação, em especial destinada para a Europa (Associação Brasileira da Indústria da Madeira Processada Mecanicamente - ABIMCI, 2001).

Ainda segundo ABIMCI (2001), enquanto a produção anual de compensados cresce na ordem de $8 \%$, o consumo de compensados no Brasil cresce anualmente em média 3\%. Associado a este menor crescimento na demanda interna Brasileira, a ABIMCI afirma que a participação das exportações brasileiras de compensado cresce anualmente cerca de $16,5 \%$.

Assim sendo, pode-se observar que a produção deste segmento está cada vez mais atrelada a exportação, cerca de $53 \%$ da produção paranaense de compensados é destinada ao mercado externo, podendo se aproximar de 70\% em épocas de maior desvalorização da moeda nacional e políticas de exportação mais propícias.

Estima-se que a produção nacional de madeira compensada está próxima de 2,3 milhões $\mathrm{m}^{3}$ / ano, concentrada em empresas de médio e grande porte (ABIMCI, 2001). Cerca de $70 \%$ da madeira compensada produzida no Brasil é fabricada no Paraná, desta forma o estudo das características da indústria no Estado reflete sobre o mercado nacional.

Uma série de mudanças na demanda por compensados já está sendo sentida com a entrada de novos painéis de madeira no mercado interno, sejam eles: o Medium Density Fibrebord (MDF) e o Oriented Strand Board (OSB). Estes painéis certamente suprirão uma certa fatia da atual demanda interna por madeira compensada, pois são destinados principalmente a movelaria e a construção civil, setores que são hoje grandes consumidores dos compensados brasileiros no mercado interno.

As conseqüências do enfraquecimento do segmento poderão ser sentidas principalmente na geração de receita e arrecadação de impostos municipais, estaduais e federais. Para vários municípios, as empresas de compensado representam muito nas suas arrecadações de impostos, na geração de renda bem como na atração de novos negócios para o município.

As questões sociais também serão afetadas, devido ao número de empregos diretos que estas empresas geram e a localização delas em pequenos municípios ao longo do Estado.

$\mathrm{O}$ enfraquecimento desse segmento também pode abalar o conjunto da cadeia produtiva do processamento mecânico da madeira como um todo, pois as empresas de compensados estão muito ligadas com outras empresas desta cadeia produtiva, afetando muitas microrregiões do Estado que tem na base florestal e nas indústrias florestais os sustentáculos da sua estrutura econômica, política, social e ambiental.

Finalmente, definir os padrões de competitividade deste segmento industrial foi a principal motivação desta pesquisa. Neste sentido o objetivo principal deste trabalho é a quantificação e análise da eficiência econômica das empresas de madeira compensada, sempre relacionando-as com as quantidades produzidas e os tipos de produtos por elas fabricados.

\section{METODOLOGIA}

Foram objeto do presente artigo as indústrias de madeira laminada e as indústrias de madeira compensada localizadas no território paranaense.

Sobre estas empresas foi realizada uma amostragem que contou com visitas pessoais as empresas durante os meses de março a maio de 2002. Nestas visitas aplicou-se um questionário, onde 39 empresas responderamno completamente, informando os seus dados econômicos, correspondendo a $32 \%$ das empresas do Estado.

Estas empresas representam 39,79\% da produção de compensados no Estado.

As empresas amostradas estão distribuídas por todas as áreas produtoras do estado e abrangem toda a amplitude de produção.

O tamanho das empresas foi obtido em consulta direta a todas as empresas citadas nos bancos de dados da FEDERAÇÃO DAS INDÚSTRIAS DO PARANÁ - FIEP (2001) e da ASSOCIAÇÃO BRASILEIRA DA INDÚSTRIA DA MADEIRA PROCESSADA 
MECANICAMENTE - ABIMCI (2002), desta forma soube-se a amplitude produtiva das empresas no estado, utilizando-se a fórmula abaixo para encontrar as classes de produção efetiva (Koehler, 1994).

$$
C P=\frac{P i}{n}
$$

Onde:

$C P=$ Classes de produção;

$P i=$ Valor da produção efetiva da maior empresa do segmento ( $\mathrm{m}^{3} /$ mês);

$n$ = Número de classes a ser dividida a população.

Dividiu-se a população em quatro classes, conforme (Silva, 1987). Devido ao pequeno número de empresas nas duas classes de maior produção, estas foram unidas em uma só.

Outra estratificação foi necessária, levando em conta os produtos produzidos pela empresa. Quando uma empresa fabricava mais de um tipo de produto, levou-se em consideração aquele que tinha maior participação no faturamento da empresa.

A definição dos produtos é descrita abaixo:

Compensado Pinus: Painel feito 100\% em lâminas de Pinus torneada, usando resina fenólica (WBP) e com medidas em geral
2,44 metros por 1,22 metros. Usado basicamente na construção civil, destinado a exportação;

Compensado Construção: Painel geralmente com capa e contra capa de lâminas de amescla torneada e miolo de Pinus, também em geral usando resina fenólica (WBP) e servindo de base para a aplicação de resina ou filme celulósico em suas faces, podendo ser usado como formas, tapumes, piso ou forro em geral;

Compensado Moveleiro: Painel com capa e contra capa de amescla torneada, e miolo em geral predominando a amescla torneada, podendo ter no interior painel sarrafeado, utilizando resina uréica (MR), ou lâminas de Pinus (compensado "Combi"), com uso restrito a lugares abrigados de umidade, tais como paredes internas, móveis, embalagens para uma única viagem;

Compensado Decorativo: Painel com capa e contra capa de madeira faqueada e miolo de amescla (principalmente) podendo ainda, as capas serem coladas em painéis sarrafeados, MDF ou aglomerados, utilizando cola uréica (MR) ou melamínica. Destinado ao uso como decoração de ambientes e na indústria moveleira.

Tabela 1: Características básicas dos grupos de produtos fabricados pelas empresas de madeira compensada Table 1: Basic caractheristics about the groups of manufactured plywood

\begin{tabular}{c|cc}
\hline TIPO DE COMPENSADO & MATÉRIA PRIMA & RESINA PREDOMINANTE \\
\hline PINUS & $100 \%$ LÂMINAS DE PINUS TORNEADAS & FENOL FORMALDEÍDO \\
CONSTRUÇÃO CIVIL & CAPA E CONTRA CAPAS DE AMESCLA & FENOL FORMALDEÍDO \\
MOVELEIRO & TORNEADAS & URÉIA FORMALDEÍDO \\
DECORATIVO & CAPA E CONTRA CAPAS DE AMESCLA & TORNEADAS \\
\hline
\end{tabular}

FONTE: POLZL (2002)

\section{Estrutura de custos}

A estrutura de custo das empresas e as análises em geral levaram em consideração informações mensais, ou seja, padronizado para o período de um mês.

Com este procedimento minimizava-se problemas tais como: sazonalidade nas vendas, mudanças na quantidade de empresas existentes e variação na quantidade produzida, pois qualquer alteração na produção das empresas deve vir de sua capacidade instalada.

\section{Custo Fixo Total (CFT)}

O conjunto de obrigações da empresa para com os recursos fixos, por unidade de tempo, são os custos fixos. No curto prazo o custo fixo permanecerá constante independendo da produção da empresa (Leftwich, 1991).

Dentro do custo fixo foram considerados os gastos com folha de pagamento operacional e administrativa, gastos com impostos e taxas que não incidem sobre a 
produção (IPTU, imposto de renda, contribuições, parcelas de dívidas), seguros, despesas de administração, aluguéis, depreciação de equipamentos e edificações (Silva, 1987).

\section{Custo Variável Total (CVT)}

As obrigações da firma incorridas com os recursos variáveis constituem os custos variáveis. Estes dependem do nível de produção e devem necessariamente aumentar a medida que a produção da firma aumenta (Leftwich, 1991).

Os custos variáveis incluem despesas com: lâminas torneadas e faqueadas; outros painéis; estoques; energia elétrica; lenha; vapor; diesel; gás; resinas e demais ingredientes da cola; fitas; colas e linhas para junção de lâminas; grampos; massa; lixas; fitas de aço; cantoneiras; tintas; corantes; gastos com transporte de lâminas e de produto acabado (porto ou revenda); custos com agentes de comércio exterior ou representantes comerciais; custos com manutenções de máquinas, equipamentos e edificações, impostos e taxa relacionados com a produção (Silva, 1987).

\section{Custo Total (CT)}

O custo total é a soma do custo fixo total com o custo variável total da empresa (Ferguson, 1994).

Onde:

$$
C T=C F T+C V T
$$

$C T=$ Custo total (R $\$ /$ mês);

$C F T=$ Custo fixo total (R\$/mês);

$C V T=$ Custo variável total (R\$/mês);

\section{Custo Total Médio (CTM)}

O custo total médio é definido pela fórmula abaixo, ele também define o custo total por unidade de produto, custo unitário (Leftwich, 1991).

$$
C T M=\frac{C T}{P}
$$

Onde:

$C T M=$ Custo total médio (R\$/mês);

$C T=$ Custo total da empresa (R $\$ /$ mês);

$P=$ Produção total efetiva de compensados da empresa ( $\left.\mathrm{m}^{3} / \mathrm{mês}\right)$.

\section{Eficiência econômica}

Índice de Eficiência Econômica

A eficiência econômica segundo Silva (1987) é baseada no custo total médio.

$\mathrm{O}$ índice de eficiência econômica não determina o quanto as empresas são eficientes individualmente, mas faz uma comparação entre elas, indicando as que possuem as melhores relações entre o custo total e a quantidade produzida. $O$ que é um bom indicador da eficiência relativa entre as empresas do segmento.

A empresa que possuir o menor custo total médio terá seu índice de custo total $\left(\mathrm{I}_{\mathrm{CT}}\right)$ igual a 100 e seu índice de eficiência econômica $\left(\mathrm{I}_{\mathrm{EE}}\right)$ igual a 1 .

As demais empresas terão os seus custos totais médios comparados com o custo total médio da empresa de $\mathrm{I}_{\mathrm{CT}}=100$. Obtido o $\mathrm{I}_{\mathrm{CT}}$, calcula-se o $\mathrm{I}_{\mathrm{EE}}$ pela fórmula abaixo.

Quanto mais alto o $\mathrm{I}_{\mathrm{EE}}$ menor é o custo total médio e mais eficiente é a empresa. $\mathrm{O} \mathrm{I}_{\mathrm{EE}}$ varia de 0,01 a 1 .

$$
I_{E E}=\frac{100}{I_{c t}}
$$

Onde:

$I_{E E}=$ Índice de eficiência econômica;

$I c t=$ Índice de custo em relação a firma mais eficiente.

Lucratividade

A lucratividade relaciona os custos e receita da empresa como um todo. Representa a quantidade de capital que sobra após subtrair o custo total da sua receita total. Também pode ser dado o nome de margem líquida de comercialização da empresa.

Para a obtenção da lucratividade em valores relativos foi utilizada a fórmula abaixo sugerida por Gonçalves (1998):

$$
L=\left[\frac{(R t-C t)}{R t}\right] \cdot 100 \text { (Valor relativo) }
$$

Onde:

$L=\quad$ Lucratividade da empresa (\%);

$R_{t}=$ Receita total (R $\$ /$ mês);

$C t=$ Custo total (R $\$ /$ mês $)$. 


\section{RESULTADOS E DISCUSSÃO}

$\mathrm{O}$ número de empresas $\mathrm{e}$ as estratificações de tamanho e produto foram obtidas através de consulta direta as empresas. Foram identificadas no estado 119 fábricas de compensado efetivamente produzindo. Outras empresas possivelmente existam, mas não produziram compensados na fase de coleta de dados ou apenas mantém em funcionamento a parte administrativa da empresa.

Para facilitar as comparações foi realizada uma classificação das empresas quanto às suas produções efetivas e amplitudes das classes (tab. 2).

Tabela 2: Quantidade de fábricas de compensado no Paraná por tamanho da produção, 2002 Table 2: Quantity of plywood enterprise size in Paraná state, 2002

\begin{tabular}{l|cc|c|c|c}
\multicolumn{1}{c}{ TAMANHO DA } & \multicolumn{1}{c}{$\begin{array}{c}\text { INTERVALO DE CLASSES } \\
\text { PROACO }\end{array}$} & \multicolumn{2}{c}{$\begin{array}{c}\text { EMPRESAS } \\
\text { EXISTENTES }\end{array}$} & $\begin{array}{c}\text { PERCENTAGEM } \\
\text { EMPRESAS }\end{array}$ & $\begin{array}{c}\text { PERCENTAGEM } \\
\text { PRODUÇÃO }\end{array}$ \\
\hline PEQUENAS & 130 & 2.450 & 101 & 84,87 & 55,49 \\
MÉDIAS & 2.451 & 4.900 & 15 & 12,61 & 29,31 \\
GRANDES & 4.901 & 9.800 & 3 & 2,53 & 15,20 \\
\hline TOTAL EMPRESAS & & & 119 & 100 & 100 \\
\hline
\end{tabular}

FONTE: Polzl (2002)

Pode-se observar que as empresas de pequeno porte representam $84,87 \%$ do número de empresas do Estado e são responsáveis por $55,49 \%$ da produção de compensados, as empresas de médio porte representam $12,61 \%$ das empresas e a produção destas é de $29,31 \%$ do total e as empresas de grande porte são $2,53 \%$ do total das empresas e representam $15,20 \%$ da produção de compensados.
Os dados acima evidenciam a importância principalmente das empresas de pequeno porte neste segmento industrial.

\section{Estrutura de custos}

A tabela 3 apresenta a estrutura de custo das empresas conforme o tamanho da produção.

Tabela 3: Estrutura de custos das empresas por classe de produção e média para o segmento, em percentual relativo, 2002

Table 3: Cost structure of plywood production by groups size and by average in the sector in relative percentual, 2002

\begin{tabular}{l|r|r|r|r}
\hline & $\begin{array}{r}\text { PEQUENAS } \\
(\%)\end{array}$ & \multicolumn{1}{c|}{$\begin{array}{c}\text { MÉDIAS } \\
(\%)\end{array}$} & $\begin{array}{c}\text { GRANDE } \\
(\%)\end{array}$ & $\begin{array}{r}\text { MÉDIA SEGMENTO } \\
(\%)\end{array}$ \\
\hline LÂMINAS E SARRAFOS & 54,95 & 54,72 & 61,50 & 54,99 \\
COMBUSTÍVEIS & 1,66 & 1,50 & 0,83 & 1,61 \\
ENERGIA ELÉTRICA & 1,79 & 1,60 & 1,49 & 1,75 \\
INSUMOS & 17,25 & 17,07 & 18,21 & 17,27 \\
TRANSPORTE & 1,95 & 4,21 & 4,22 & 2,46 \\
COMERCIALIZAÇÃO & 5,28 & 6,14 & 1,99 & 5,38 \\
MANUTENÇÕES & 1,58 & 1,50 & 0,99 & 1,55 \\
\hline CUSTO VARIÁVEL TOTAL & 84,45 & 86,73 & 89,24 & 5,01 \\
\hline ADMINISTRAÇÃO & 6,53 & 3,49 & 0,17 & 5,77 \\
MÃO DE OBRA E ENCARGOS & 9,02 & 9,77 & 10,60 & 9,23 \\
\hline CUSTO FIXO TOTAL & 15,55 & 13,27 & 10,76 & 14,99 \\
\hline CUSTO TOTAL & 100 & 100 & 100 & 100 \\
\hline
\end{tabular}

NOTA: Dados coletados e processados pelo autor

Os custos com matéria prima, representam cerca de $55 \%$ do custo total médio encontrado para as fábricas de madeira compensada no Paraná. Os ingredientes para cola e demais insumos usados na produção representam mais de $17 \%$ do custo total e os custos com energia e combustível representam cerca de 3\% desse custo. Os demais itens (transporte, comercialização e manutenções) representam aproximadamente $10 \%$ do custo total. O custo variável contribui com $85 \%$ do custo total e por conseqüência o custo fixo representa cerca de $15 \%$. 
A comparação das empresas agrupadas pelas suas quantidades produzidas, mostra um decréscimo nos custos fixos com o aumento da produção, indo de $15,55 \%$ nas pequenas empresas, $13,27 \%$ nas empresas médias e $10,76 \%$ nas empresas grandes.

Comparando a estrutura de custos obtida por Silva (1987), observa-se que em 15 anos os custos com matéria prima caíram cerca de $27 \%$, o que em parte é conseqüência da entrada forte do Pinus como matéria prima, mas também devido ao aumento da importância de outros custos na estrutura de custos.

Um custo que aumentou neste período foi o custo administrativo, que antes não passava de 1,74\% e agora está em 5,77\%. Sabendo-se que boa parte deste custo deve-se ao pagamento de taxas e impostos, supõe-se que estes estão contribuindo mais para o custo total.

Na tabela 4 apresenta-se a estrutura de custos obtida nas empresas de madeira compensada por tipo de produto.

Tabela 4: Estrutura de custos das empresas por tipo de produto, 2002

Table 4: Cost structure of plywood by tyre of product, 2002

\begin{tabular}{l|r|r|r|r}
\hline & $\begin{array}{c}\text { PINUS } \\
(\%)\end{array}$ & $\begin{array}{c}\text { CIVIL } \\
(\%)\end{array}$ & $\begin{array}{c}\text { MOVELEIRO } \\
(\%)\end{array}$ & $\begin{array}{c}\text { DECORATIVO } \\
(\%)\end{array}$ \\
\hline LÂMINAS E SARRAFOS & 52,82 & 50,12 & 61,45 & 62,43 \\
COMBUSTÍVEIS & 1,90 & 1,89 & 1,06 & 0,92 \\
ENERGIA ELÉTRICA & 2,21 & 1,58 & 1,36 & 1,11 \\
INSUMOS & 19,85 & 18,89 & 11,97 & 13,46 \\
TRANSPORTE & 3,84 & 1,84 & 1,72 & 0,16 \\
COMERCIALIZAÇÃO & 4,92 & 6,07 & 4,88 & 6,27 \\
MANUTENÇÕES & 1,77 & 1,57 & 1,31 & 1,10 \\
\hline CUSTO VARIÁVEL TOTAL & 87,31 & 81,97 & 83,74 & 85,45 \\
\hline ADMINISTRAÇÃO & 3,21 & 7,73 & 7,92 & 7,05 \\
MÃO DE OBRA E ENCARGOS & 9,48 & 10,30 & 8,34 & 7,49 \\
\hline CUSTO FIXO TOTAL & 12,69 & 18,03 & 16,26 & 14,55 \\
\hline CUSTO TOTAL & 100 & 100 & 100 & 100 \\
\hline
\end{tabular}

NOTA: Dados coletados e processados pelo autor

Quando se agrupa as empresas que fabricam produtos similares observa-se que o custo com o insumo madeira é maior nas empresas de compensado decorativo e moveleiro (mais de $60 \%$ do custo total) e menor para as empresas de compensado de Pinus e para Construção Civil (próximos a $51 \%$ ). O custo fixo é menor nas empresas que fabricam compensados de Pinus (13\%), subindo para $14,5 \%$ naquelas que fabricam compensado decorativo, $16 \%$ nas empresas de compensado moveleiro e tendo o seu mais alto valor nas empresas de compensado para construção civil, $18 \%$ do custo total.

\section{Índice de Eficiência Econômica}

A tabela 5 apresenta os Índices de eficiência econômica (IEE) das empresas de madeira compensada amostradas, por tamanho da produção.

Tabela 5: Índice de eficiência econômica das empresas de compensado por tamanho da produção, 2002 Table 5: Economic eficiency index to plywood firms by productive size groups

\begin{tabular}{l|r}
\hline \multicolumn{1}{c}{ EMPRESAS } & ÍNDICE DE EFICIÊNCIA ECONÔMICA \\
\hline PEQUENA & 63,90 \\
MÉDIA & 85,60 \\
GRANDE & $100,00 *$ \\
\hline SEGMENTO & 66,90 \\
\hline
\end{tabular}

NOTA: Dados coletados e processados pelo autor

* Possui dados de apenas de uma empresa 
$\mathrm{O}$ índice de eficiência econômica (IEE) relaciona as empresas entre si utilizando os seus custos totais médios, sempre comparando a empresa de menor custo total médio com as demais.

Quanto mais próximo do 100 estiver a média do IEE menor será o custo médio das empresas analisadas e mais eficientes economicamente serão.

O IEE do segmento na média foi de $66,90 \%$, superior em $33,1 \%$ ao da empresa de menor custo médio total. Esta eficiência estava próxima do índice encontrado para as empresas pequenas que foi de $63,90 \%$. As empresas médias possuíam um IEE de 85,60\%.

Não foi possível obter um IEE representativo para as empresas grandes, pois embora as 3 empresas de grande porte tenham sido visitadas apenas uma forneceu os dados econômicos da empresa.

A tabela 6 apresenta o resultado obtido para o Índice de Eficiência Econômica (IEE) das empresas de madeira compensada no Paraná, por tipo de produto fabricado.

Tabela 6: Índice de eficiência econômica das empresas de compensado por tipo de produto, 2002

Table 6: $\quad$ Economic eficiency index to plywood enterprises by type of product,2002

\begin{tabular}{l|c} 
Table 6: & Economic eficiency index to plywood enterprises by type of product,2002 \\
\hline \multicolumn{1}{c}{ EMPRESAS } & ÍNDICE DE EFICIÊNCIA ECONÔMICA \\
(\%) & 87,50 \\
PINUS & 64,60 \\
CONSTRUÇÃO CIVIL & 75,00 \\
MOVELEIRO & 71,50 \\
DECORATIVO
\end{tabular}

NOTA: Dados coletados e processados pelo autor

O IEE médio das empresas de compensados de Pinus foi o maior dentre os grupos de empresas $(87,50 \%)$. As empresas que fabricam compensados moveleiros possuíam o segundo melhor índice (75\%). Enquanto as empresas de compensados decorativos tiveram IEE médio de $71,50 \%$ e as empresas de compensado para construção civil obtiveram o pior desempenho, IEE de $64,50 \%$.

\section{Lucratividade da Empresa}

A tabela 7 apresenta a Lucratividade média das empresas de madeira compensada no Paraná, bem como a Lucratividade das empresas por tamanho da produção.

Tabela 7: Lucratividade das empresas de compensado pelo tamanho das suas produções, 2002

Table 7: $\quad$ Profitability of plywood enterprises by production size group, 2002

\begin{tabular}{l|c}
\hline \multicolumn{1}{c|}{ EMPRESAS } & LUCRATIVIDADE \\
& $(\%)$ \\
\hline PEQUENA & 11,61 \\
MÉDIA & 16,90 \\
GRANDE & 13,72 \\
\hline MÉDIA DAS EMPRESAS & 12,72 \\
\hline NOTA: Dados coletados e processados pelo autor
\end{tabular}

A lucratividade média do segmento da madeira compensada no Paraná é de $12,72 \%$. A maior lucratividade do segmento está nas empresas de tamanho médio $(16,9 \%)$, seguido pelas empresas de grande porte $(13,72 \%)$ e as empresas de pequeno porte $(11,61 \%)$.

A tabela 7 apresenta a margem líquida das empresas de madeira compensada pelo tipo de produção.
As empresas de grande porte fabricam compensados de Pinus, mas estas não estavam obtendo bons preços, durante os meses da pesquisa. Isto ocasionou a baixa lucratividade, desta forma inerentes ao tipo de produção e não ao tamanho da produção.

A tabela 8 apresenta a lucratividade das empresas de madeira compensada pelo tipo de produção. 
Tabela 8: Lucratividade das empresas de compensado pelo tipo de suas produções, 2002

Table 8: Profitability of plywood enterprises by type of product, 2002

\begin{tabular}{l|cc}
\multicolumn{1}{c}{ EMPRESAS } & $\begin{array}{c}\text { MARGEM LÍQUIDA } \\
(\%)\end{array}$ \\
\hline PINUS & & 11,07 \\
CONSTRUÇÃO CIVIL & 11,44 \\
MOVELEIRO & 13,56 \\
DECORATIVO & 19,55 \\
\hline
\end{tabular}

NOTA: Dados coletados e processados pelo autor

As empresas que fabricam compensados decorativos são as que possuem lucratividade maior, a média para elas é de $19,55 \%$, muito superior a lucratividade das fábricas de compensado moveleiro $(13,56 \%)$, das fábricas de compensado para construção civil (11,44\%). A lucratividade mais baixa foi encontrada para as fábricas de compensado de Pinus (11,07\%), sendo que este baixo valor é reflexo dos baixos preços que este tipo de compensado estava tendo na época.

\section{CONCLUSÃO E RECOMENDAÇÕES}

A estrutura de custos das empresas está se deslocando, os custos com matéria prima, insumo e trabalho estão representado menos no custo total que a 15 anos atrás, em contra partida os custos com administração aumentaram significativamente.

Do ponto de vista da eficiência econômica, as empresas de grande porte são as mais competitivas, seguidas pelas empresas de médio porte, conseqüentemente as empresas de pequeno porte possuem os piores índices de eficiência sendo geralmente as menos competitivas.

As empresas de compensados decorativos são as empresas que possuem maior competitividade no segmento, elas possuem os melhores índices relacionados a relação custo total e receita líquida (Lucratividade) e bons índices econômicos referentes ao Índice de Eficiência Econômica (minimização do custo total médio).

As empresas com menor eficiência econômica, conseqüentemente maior vulnerabilidade às mudanças econômicas do mercado, são as empresas de compensado para construção civil, tendo em vista que a lucratividade das empresas de compensados de Pinus tende a ser maior, pois está bastante presa ao preço internacional e a política de exportações brasileira.
As empresas que fabricam compensados no mundo todo estão passando por reestruturações, sendo que no Brasil e, principalmente no Paraná, estas adequações são necessárias. Este é o momento para repensar estratégias econômicas e produtivas para o segmento. Pois embora muito seja falado sobre a decadência desta indústria, determinadas partes dela apresentam bons índices econômicos, de lucratividade e competitividade.

\section{REFERÊNCIAS}

ASSOCIAÇÃO BRASILEIRA DA INDÚSTRIA DA MADEIRA PROCESSADA MECANICAMENTE. Estudo setorial. Curitiba: ABIMCI, 2001.

ASSOCIAÇÃO BRASILEIRA DA INDÚSTRIA DA MADEIRA PROCESSADA MECANICAMENTE. Relação dos endereços dos seus associados. Curitiba: ABIMCI, 2002.

FEDERAÇÃO DAS INDÚSTRIAS DO PARANÁ - FIEP. Cadastro das Indústrias do Estado do Paraná 2000, Curitiba, 2001.

FERGUSON C. E. Microeconomia. 18. ed. Rio de Janeiro: Forense Universitária, 1994.

GONÇALVES S. L. F. Análise da indústria do segmento laminado e compensado do estado do Amazonas, 1996. Curitiba : UFPR, 1998. Dissertação (Mestrado em Ciências Florestais) - Setor de Ciências Agrárias, Universidade Federal do Paraná.

KOEHLER, H. S. Estatística experimental. Curitiba. Universidade Federal do Paraná. 1994,125 p.

LEFTWICH, R. H. O sistema de Preços e a Alocação de Recursos. São Paulo: Livraria Pioneira Editora. 1991.7 ed.. 453 p. 
Eficiência econômica do segmento...

POLZL, W. B. Eficiência produtiva e econômica do segmento indústria da madeira compensada no estado do Paraná. Curitiba, 2002. Dissertação (Mestrado em Ciências Florestais ) - Setor de Ciências Agrárias, Universidade Federal do Paraná.

SILVA, J. C. G. L. da. Análise da eficiência econômica da indústria de compensados do estado do Paraná. Curitiba, 1987. Dissertação (Mestrado em Ciências Florestais) - Setor de Ciências Agrárias, Universidade Federal do Paraná. 